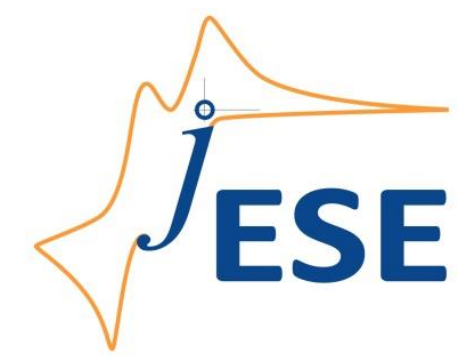

Open Access : : ISSN 1847-9286

www.jESE-online.org

Original scientific paper

\title{
Comparative voltammetric study and determination of carbamate pesticide residues in soil at carbon nanotubes paste electrodes
}

\author{
THOMMANDRU RAVEENDRANATH BABU, SARVAREDDY RAJASEKHAR REDDY $\bowtie$, \\ PUCHAKAYALA SUJANA
}

Electroanalytical Lab., Department of Chemistry, N.B.K.R. Science and Arts College, Vidyanagar, Nellore, AP, India

${ }^{\square}$ Corresponding Authors: E-mail: sarvareddymadhavi@gmail.com

Received: October 22, 2013; Revised: November 7, 2013; Published: January 25, 2014

\begin{abstract}
In this investigation, the persistence of carbamate pesticides in soil samples was investigated. A simple and selective differential pulse adsorptive stripping voltammetry was selected for this investigation. Carbon nanotubes paste electrodes were used as working electrodes for differential pulse adsorptive stripping voltammetry and cyclic voltammetry. A symmetric study of the various operational parameters that affect the stripping response was carried out by differential pulse voltammetry. Peak currents were linear over the concentration range of $10^{-5}$ to $10^{-10} \mathrm{M}$ with an accumulation potential of $-0.6 \mathrm{~V}$ and a $70 \mathrm{~s}$ accumulation time with lower detection limits of $1.09 \times 10^{-7} \mathrm{M}, 1.07 \times 10^{-7} \mathrm{M}, 1.09 \times 10^{-7} \mathrm{M}$ for chlorphropham, thiodicarb, aldicarb. The relative standard deviation $(n=10)$ and correlation coefficient values were $1.15 \%, 0.988 ; 1.13 \%$, 0.978 ; and $1.14 \%, 0.987$, respectively. Universal buffer with $\mathrm{pH}$ range $2.0-6.0$ was used as supporting electrolyte. The solutions with uniform concentration $\left(10^{-5} \mathrm{M}\right)$ were used in all determinations. Calculations were made by standard addition method.
\end{abstract}

\section{Keywords}

Thiodicarb; Aldicarb; Chlorpropham; Differential pulse adsorptive stripping voltammetry; Cyclic voltammetry; CNTPE; Soil samples

\section{Introduction}

Pesticides are extensively and indiscriminately used in modern agricultural practices, resulting in widespread distribution in the environment and posing serious health hazards to animals and human beings. Besides inhalation from polluted environment, animals are also exposed to pesticides through the utilisation of treated feeds and fodders. Thiodicarb (dimethyl $N, N^{\prime}$-thiobis 
(methyl imino) carbonyloxy bisethanimido thioate) is a new carbamate compound with a broad spectrum of activity that is being extensively used for crop protection. It is a class II category compound (moderately toxic) as set forth by the United States Environmental Protection Agency (USEPA) and World Health Organization (WHO). Various carbamate compounds have been reported to cause biochemical changes in different species of animals [1-5]. Little information on the effect of thiodicarb on biochemical profiles is available in dogs and rats [6-8]. However, no detailed report is available regarding the effects of thiodicarb on various biochemical parameters and blood enzymes in animals.

\section{Chlorpropham $\left(\mathrm{C}_{10} \mathrm{H}_{12} \mathrm{ClNO}_{2}\right)$}

Chlorpropham is a plant growth regulator used for the pre-emergence control of grass weeds in alfalfa, Lima and snap beans, blueberries, cane berries, carrots, cranberries, ladino clover, garlic, seed grass, onions, spinach, sugar beets, tomatoes, safflower, soybeans, gladioli and woody nursery stock. It is also used to inhibit potato sprouting and for sucker control in tobacco. Parilla et al. [9] reported SPE and HPLC/DAD methods to determine pesticide residues in water. Richard [10] employed HPLC method to determine carbamate residues using post-column hydrolysis electrochemical detection. Aulakh et al. [11] reported solid phase microextraction HPLC for the analysis of pesticides. Tomomi et al. [12] developed a new analytical method for the determination of nine pesticide residues including chlorpropham in fruits and vegetables using ESI-LC/MS/MS with direct sample injection into a short column. Oosselton and Snelling [13] reported the use of GLC, HPLC/DAD and TLC for the determination of 51 common pesticides including chlorpropham.

\section{Thiodicarb $\left(\mathrm{C}_{10} \mathrm{H}_{18} \mathrm{~N}_{4} \mathrm{O}_{4} \mathrm{~S}_{3}\right)$}

Thiodicarb is a non-systemic carbamate insecticide whose acetyl cholinesterase activity is related to its main methomyl degradation product[14]. Xu and Li [15] determined thiodicarb by reverse-phase high performance liquid chromatography.

Aldicarb $\left(\mathrm{C}_{7} \mathrm{H}_{14} \mathrm{~N}_{2} \mathrm{O}_{2} \mathrm{~S}\right)$

Aldicarb is a carbamate insecticide which is the active substance in the pesticide Temik. It is effective against thrips, aphids, spider mites, lygus, fleahoppers, and leafminers, but is primarily used as a nematicide. Waliszewski and Szymczyński [16] reported a Simple method for the gaschromatographic determination of aldicarb, aldicarb sulphoxide and aldicarb sulphone in soil and sugar beets. Mora et al. [17] determined the presence of the nematicide aldicarb and its metabolites aldicarb sulphoxide and aldicarb sulphone in soils and potatoes by liquid chromatography with photodiode array detection. Although there are reports in the literature for several methods of determinations of pesticides, there are few focused on electrochemical methods; hence, in this investigation, electrochemical determinations [18-20] were employed.

\section{Experimental}

\section{Apparatus and electrodes}

The electrochemical measurements were carried out with Metrohm model 101 potentiostat and galvanostat. The three-electrode system consisted of carbon nanotubes paste electrode as the working electrode, $\mathrm{Ag} / \mathrm{AgCl}$ reference electrode and a platinum wire auxiliary electrode. The electrodes joined the cell through holes in its Teflon cover. All of the potentials given in this work were measured with respect to this reference system. Electrochemical experiments were carried out in a voltammetric cell at room temperature. A magnetic stirrer was used during the 
accumulation step. The Elico Li-129 model glass calomel combined electrode was employed for measuring $\mathrm{pH}$ values.

\section{Preparation of carbon nanotubes paste electrode}

The CNTPE was prepared by mixing multiwall CNTs powder (diameter $20-50 \mathrm{~nm}$, either 1-5 mm or 5-20 mm lengths) and Castrol oil in an agate mortar at a ratio of $50.0 \%(\mathrm{w} / \mathrm{w})$ each. A portion of the resulting paste was packed firmly into the cavity $(0.8 \mathrm{~mm}$ diameter $)$ of a Teflon tube. The electrical contact was established via a copper wire [21].

\section{Reagents and solutions}

All reagents used were of analytical reagent grade. Double distilled water was used throughout the analysis. In the present investigation, universal buffers in the $\mathrm{pH}$ range 2.0 to 6.0 were used as supporting electrolytes and were prepared using $0.2 \mathrm{M}$ boric acid, $0.05 \mathrm{M}$ citric acid and $0.1 \mathrm{M}$ trisodium orthophosphate solutions. Samples were obtained from RANKEM India, Ltd.

\section{Result and discussion}

All of the compounds exhibit well-defined voltammetric peaks at the same experimental conditions but the reduction electrode potentials are somewhat different; this is attributed to the difference in the nature of groups present in the compounds under investigation (Scheme 1).

Although all of the compounds possess electron-donating nitrogen on one or both sides of carbonyl carbon, there are some differences in the environment of carbonyl carbon.

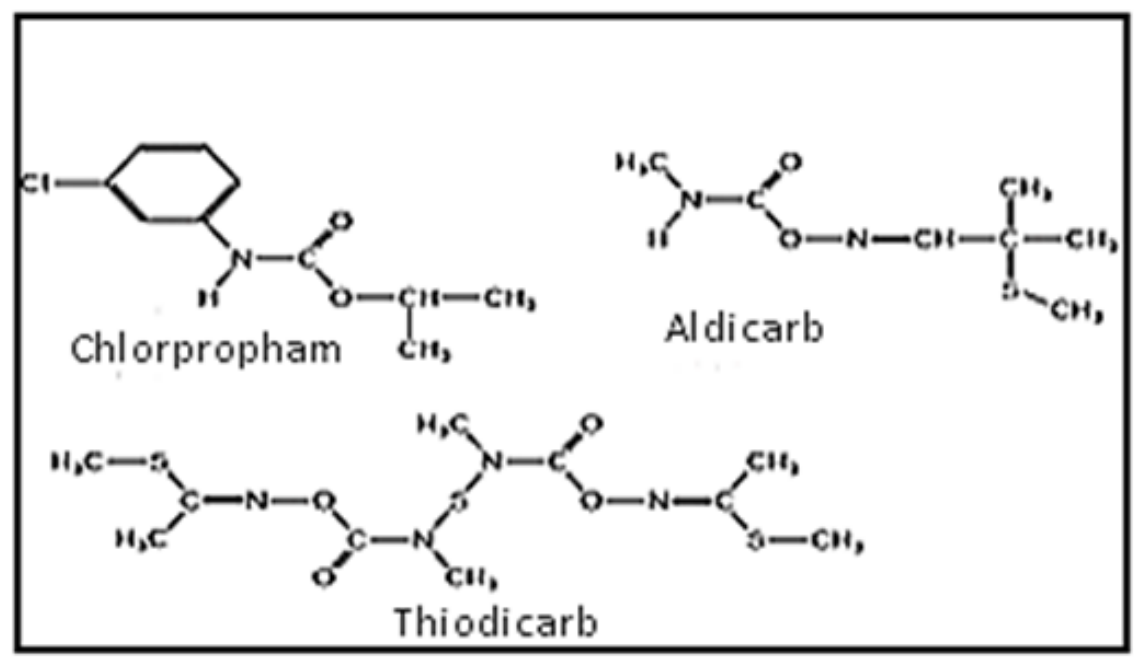

Scheme 1. Structures of the pesticides investigated in this work

In the case of chlorpropham, there is oxygen bonded with a propyl group on one side of the carbonyl carbon and on the other side nitrogen with chlorobenzene. Because the aromatic ring is closer to the electroactive group, it will experience less negative charge and undergo reduction at somewhat lower electrode potentials when compared with the other two carbonyl groupcontaining pesticides. Two electrons are involved in reduction of one carbonyl group into the hydroxyl group.

In the case of thiodicarb, there are two carbonyl groups with the same environments; in the case of two carbonyl groups, there is oxygen bonded with electron-donating nitrogen on one side and nitrogen bonded with electronegative sulphur and electron-donating alkyl groups on the other side along with the other carbonyl group with the same environment. In the case of thiodicarb, however, there is electron-donating nitrogen, alkyl groups with positive inductive effect; their 
impact on the electronic environment seems to be nil because of double bonds and electronegative groups. In the case of thiodicarb, there is a well-defined peak due to 4 electron reduction of two carbonyl groups.

In the case of aldicarb, there is only one carbonyl group on one side with nitrogen, while there is electronegative oxygen bonded with nitrogen on the other side. Because of the electro rich nitrogen being directly bonded with a carbonyl group, the environment around the electroactive species seems to be more negative and reduction will take place at greater negative potentials compared with the remaining two pesticides. Two electron reductions will take place.

Figure 1 shows DP-AdSV response for the samples $\left(10^{-5} \mathrm{M}\right)$ under investigation over the $\mathrm{pH}$ range 2.0-6.0 at CNTPE. The systematic studies of the various experimental and instrumental parameters that affect the voltammetric response were carried out in order to establish the optimum conditions. The $\mathrm{pH}$ of a solution is a critical factor affecting both the rate and equilibrium state of the reduction process, as well as the rate of the electrode reaction. The influence of $\mathrm{pH}$ on the voltammetric response was studied at CNTPE of the $10^{-5} \mathrm{M}$ samples with pH between 2.0 and 6.0. The maximum peak currents were obtained with $\mathrm{pH}$ 4.0. Voltammograms obtained for increasing values of the scan rate showed the existence of a linear dependence of the peak current intensity on the scan rate between 10 to $60 \mathrm{mV} \mathrm{s}^{-1}$ The peak currents were directly proportional to the scan rate. The voltammetric behaviour of samples has been studied in the $\mathrm{pH}$ range from 2.0 to 6.0. A single well resolved peak was observed throughout the $\mathrm{pH}$ range and this single peak is attributed to the reduction of corresponding groups. All the compounds under investigation exhibit only one voltammetricpeak for each over the $\mathrm{pH}$ range 2.0 to 6.0. This wave / peak are attributed to the simultaneous reduction of carbonyl group. Typical cyclic voltammograms are shown in Fig. 2. No reduction peak is observed in basic medium $(8 \leq \mathrm{pH} \leq 12)$ for carbonyl groups due to the precipitation. The diffusion controlled nature of electrode process is evidenced from the linear plots of $i_{\mathrm{p}}$ vs. $V^{1 / 2}$ (Fig. 3).

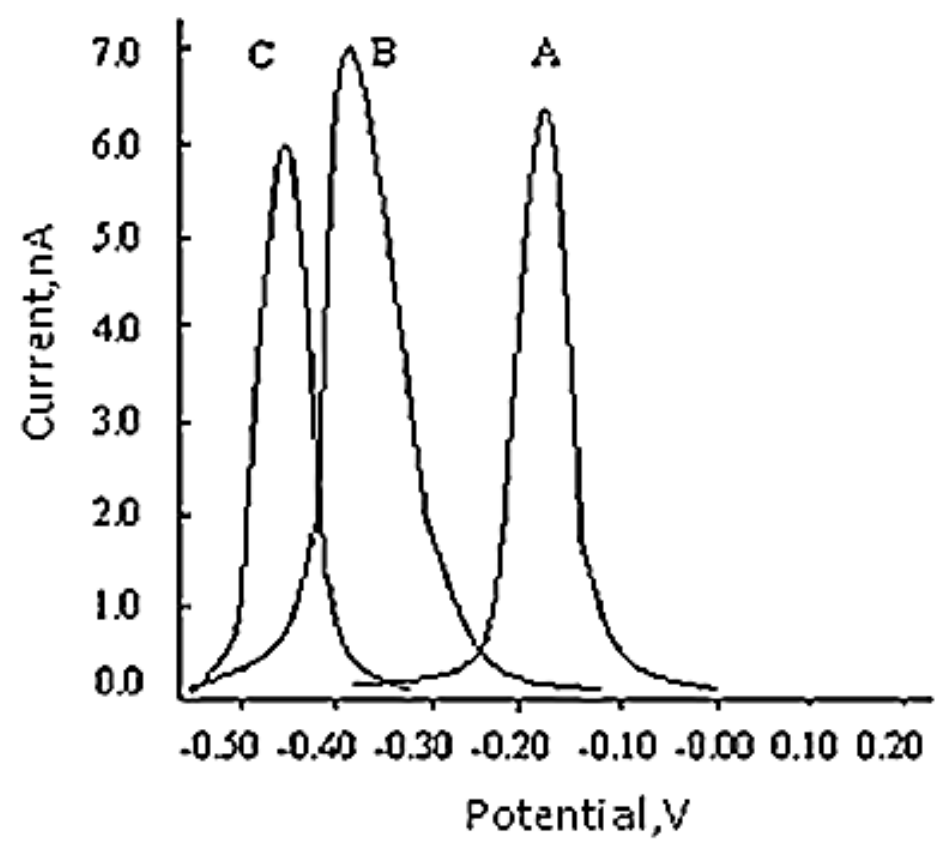

Fig. 1.Stripping voltammograms of $A$ - chlorpropham, $B$ - thiodicar and $C$-aldicarb at CNTPE Concentration: $10^{-5} \mathrm{ML}^{-1}$, scan rate: $60 \mathrm{mV} \mathrm{s}^{-1}, \mathrm{pH} 4.0$ 


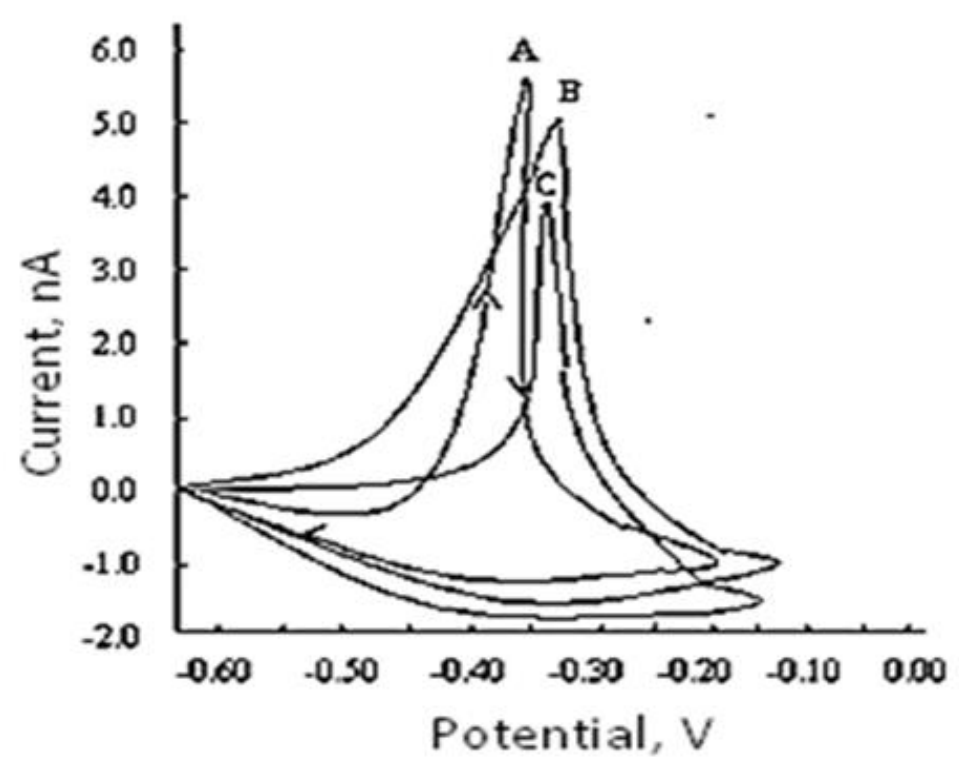

Fig. 2. Cyclic voltammograms of $A$ - chlorpropham, $B$ - thiodicar and $C$ - aldicarb at CNTPE, Concentration: $10^{-5} \mathrm{ML}^{-1}$, scan rate: $60 \mathrm{mV} \mathrm{s}^{-1}, \mathrm{pH} 4.0$

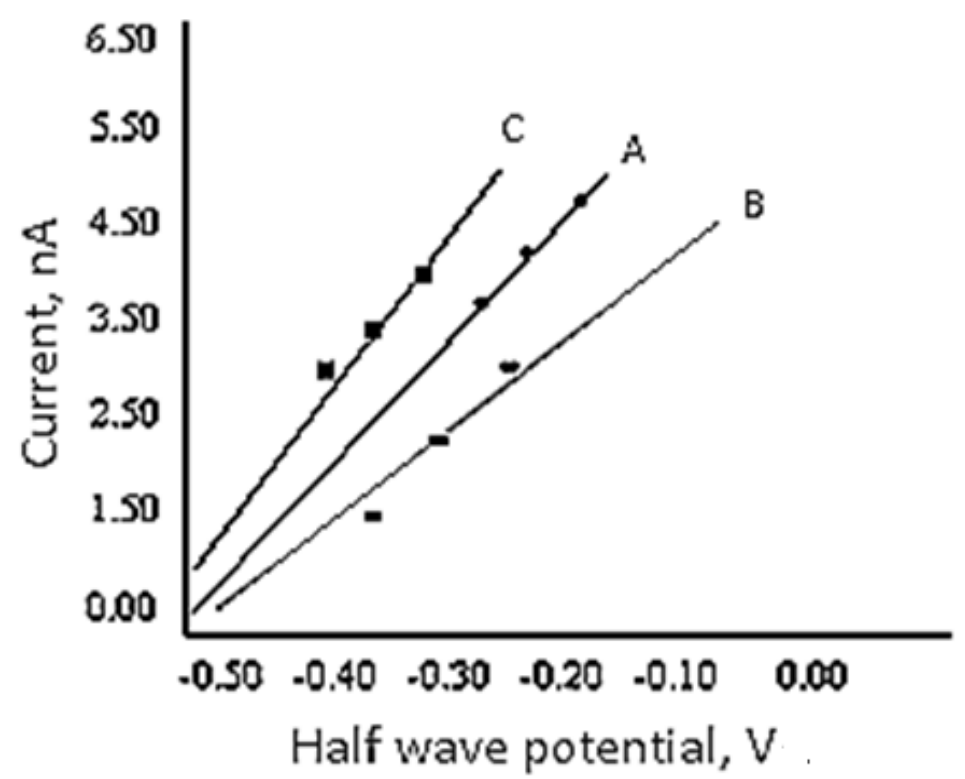

Fig. 3. $I_{p}$ vs. $V^{1 / 2}$ plots of $A$ - chlorpropham, $B$ - thiodicarb, $C$ - aldicarb. Concentration: $10^{-5} \mathrm{ML}^{-1}$; Scan rate: $60 \mathrm{mV} \mathrm{s}^{-1}, \mathrm{pH} 4.0$

\section{Recovery experiments}

Analysis

Based on the results obtained with differential pulse adsorptive stripping voltammetry and cyclic voltammetry at CNTPE, differential pulse adsorptive stripping voltammetry and cyclic voltammetry have been used for the quantitative determination of samples using both calibration and standard addition methods. The investigated compounds were found to exhibit well resolved peaks at $\mathrm{pH} 4.0$, and the sharp well resolved peak was chosen for quantitative studies. Peak currents are linear over the concentration range of $10^{-5}$ to $10^{-10} \mathrm{M}$ with lower detection limits of $1.09 \times 10^{-7} \mathrm{M}$ for chlorpropham, $1.07 \times 10^{-7} \mathrm{M}$ for thiodicarb, and $1.09 \times 10^{-7} \mathrm{M}$ for aldicarb. The relative standard deviation and correlation coefficients were found to be $1.15 \%, 0.988 ; 1.13 \%$, 0.978 ; and $1.14 \%, 0.987$, respectively, for 10 replicates. 


\section{Determination of pesticide samples from their standard solutions}

To check the validity of the method, a standard solution $\left(10^{-5} \mathrm{M}\right)$ was prepared in dimethyl formamide. $1 \mathrm{~mL}$ of the standard solution was transferred into a voltammetric cell and made up with $9 \mathrm{~mL}$ of supporting electrolyte $(\mathrm{pH} \mathrm{4.0)}$ ), before being deoxygenated with nitrogen gas for $10 \mathrm{~min}$, and then subjected to voltammetry. After obtaining voltammograms, a small increment of the standard solution of samples was added to voltammetric cells and was deoxygenated for $10 \mathrm{~min}$; voltammograms were recorded under similar conditions. In the same manner, 10 voltammograms were recorded for 10 standard additions. The optimum conditions for analytical determination were found to be at $\mathrm{pH} 4.0$ and scan rate $60 \mathrm{mV} \mathrm{s}^{-1}$. The average recovery obtained for the pesticide samples in soil samples ranged from 89.00 to $92.00 \%$ for chlorpropham, from 97.50 to $99.33 \%$ for thiodicarb and from 97.80 to $98.33 \%$ for aldicarb for 10 replicates. The results are shown in Table 1.

Table 1. Recoveries of chlorpropham, thiodicarb, aldicarb in standard solution of $1.0 \times 10^{-5} \mathrm{M}$

\begin{tabular}{lcccc} 
Sample & Amount added, $\mu \mathrm{g} \mathrm{mL}^{-1}$ & Amount found, $\mu \mathrm{gL}^{-1}$ & *Recovery, \% & Standard deviation \\
\hline Chlorpropham & 3.0 & 2.79 & 93.00 & 0.024 \\
\hline Thiodicarb & 3.0 & 2.98 & 99.33 & 0.034 \\
\hline Aldicarb & 3.0 & 2.95 & 98.33 & 0.028 \\
\hline
\end{tabular}

*Average of 10 replicates

\section{Determination of pesticide samples in spiked soil samples}

The soil under investigation was spiked with known amounts of formulations and dried on filter paper at laboratory temperature. For extraction, $50 \mathrm{~g}$ of the dried soil was transferred into a $250 \mathrm{ml}$ Erlenmeyer flask. These samples and blanks were extracted 2-5 times by acetone. The extracts were then evaporated to dryness and the resulting residues were dissolved in DMF and transferred to $50 \mathrm{ml}$ voltammetric flasks. This solution was filtered through Whatman nylon membrane filter paper and voltammograms of the filtrates were recorded by following the previously mentioned procedure. The average recovery obtained for the sample in soil samples ranged from 90.00 to $93.00 \%$ for chlorpropham (bud nip), from 93.50 to $95.66 \%$ for thiodicarb (larvin) and from 92.70 to $95.66 \%$ for aldicarb (aldicarb sulphone) for 10 replicates. The results are presented in Table 2.

Table 2. Recoveries of chlorpropham, thiodicarb, aldicarb (formulations) in spiked soil samples

\begin{tabular}{lcccc} 
Sample & Amount added, $\mu \mathrm{g} \mathrm{mL}^{-1}$ & Amount found, $\mu \mathrm{g} \mathrm{mL}^{-1}$ & *Recovery, \% & Standard deviation \\
\hline Bud Nip & $\mathbf{3 . 0}$ & 2.76 & 92.00 & 0.015 \\
\hline Larvin & $\mathbf{3 . 0}$ & 2.87 & 95.66 & 0.024 \\
\hline Aldicarb sulphone & $\mathbf{3 . 0}$ & 2.88 & 96.00 & 0.018 \\
\hline
\end{tabular}

*Average of 10 replicates

\section{Conclusion}

In conclusion, the adopted method of differential pulse adsorptive stripping voltammetry is a less tedious and economically low consumption method; hence, this can be used satisfactorily for the determination of pesticide residues in soil. The obtained results also demonstrate the 
suitability of the developed DP-AdSV method for the determination of samples under investigation in soil samples. The electrochemical reduction mechanism of the carbonyl group in all three compounds was found to be irreversible. The nature of the electrode process for these compounds is found to be diffusion controlled and involves adsorption on the electrode surface without any kinetic complications. The variation of peak current with the $\mathrm{pH}$ of the supporting electrolyte influences the diffusion coefficient values. The slight variations in diffusion coefficient values with increasing $\mathrm{pH}$ may be attributed to a decrease in the availability of protons.

The heterogeneous forward rate constant values obtained for the reduction of these three pesticides are found to decrease with an increase in the $\mathrm{pH}$ of the solution, as expected. From the comparison of the forward rate constant values of the three compounds, it can be seen that they reduce at different electrode potentials, which is attributed to the difference in the molecular environment of the samples under investigation. Analytical procedures are described for the quantitative determination of these compounds using DP-AdSV. In the present investigation, standard addition and calibration methods were utilised for the determination of these pesticides in soil samples. From the recoveries, it has been observed that the proposed method describes the successful application of an electroanalytical technique for the analysis of these compounds. It also demonstrates that DP-AdSV at a carbon nanotubes paste electrode could conveniently be used for the quantitative determination of these pesticides in soil samples. The method shows a good reproducibility and high accuracy compared with spectrophotometric, spectrofluorimetric and chromatographic methods of analysis.

\section{References}

[1] M. Jayapragasam, I. Jasmine, V.,Thenammai, R. Kasthuri, Madras Agric. J. 68 (1981) 461465

[2] R. Kiran, M. Sharma, R. C. Bansal Pesticides 19 (1985) 42-43.

[3] G. L. Kennedy, J. Appl. Toxicol. 6 (1986) 423-429.

[4] S. D. Moregaonkar, B. B .Deshpande, V. P Vadlmudi, N. M. Degloorkar, S. R. Rajurkar, Indian. Vet. J. 70 (1993) 945-948.

[5] Satpal, S. K. Jain, J. S. Punia, Toxicol. Int .17 (2010) 30-32.

[6] EFSA Scientific Report, 55 (2005) 1-76

[7] H. B. Knaak, B. W .Wilson. ACS Symposium Series, 273 (1985) 63-79.

[8] N. N. Hamada, Rep. No. 210-216 from Hazleton Laboratories America Inc., Vienna, VA to Union Carbide Agricultural Products Company Inc. Research Triangle Park, North Carolina, 1986

[9] P. Parrilla, J. L. M. Vidal, Anal. Lett. 30 (1997) 1719-1738.

[10] R. T. Krause, J. Chromatogr. A 442(1988) 333-343.

[11] J. S. Aulakh; A. K. Malik, V. Kaur, P. Schmitt-Kopplin, CRC Cr. Rev. Anal. Chem. 35_(2005) 7185.

[12] T. Goto, Y. Ito, S. Yamada, H. Matsumoto, H. Oka and. H. Nagase, Anal. Chim. Acta 555 (2006) 225-232.

[13] M. D. Osselton, R. D. Snelling J. Chromatogr. A 368 (1986) 265-271.

[14] G. Hoizey, F. Canas, L Binet, M. L. Kaltenbach, G. Jeunehomme, M. H. Bernard, D. Lamiable, J. Forensic Sci. 53 (2008) 499-502.

[15] G. Xu, W. Zheng, Y. Li, S. Wang, J. Zhang, Y. Yan., Int. Biodeter. Biodegr. 62 (2008) 51-56.

[16] S. M. Waliszewski, G. A. Szymczyński, Fresen. J. Anal. Chem. 338 (1990) 75-76

[17] N. Unceta, A. Ugarte, A. Sanchez, A. Gómez-Caballero, M. A .Goicolea, R. J. Barrio, J. Chromatogr. A 1061 (2004) 211-216 
[18] S. Rajasekharreddy, K. Chandramohan and, NY. Sreedhar, Int. J. Sci. Eng. Res, 2(10) (2011) 1-4.

[19] S. Rajasekhar Reddy, T. Raveendranath Babu, B. Sreenivasululnt, J. Res. Pharm. Life Sci. 1 (2013) 43-47.

[20] S. Rajasekhar Reddy, T. Raveendra Nath Babu, Int. J. Nanosci.12 (2013) 130058.

(C) 2014 by the authors; licensee IAPC, Zagreb, Croatia. This article is an open-access article distributed under the terms and conditions of the Creative Commons Attribution license (http://creativecommons.org/licenses/by/3.0/) (cc) EY 